\title{
The effects of nonsynchronous trading in the Brazilian capital market
}

\author{
Danilo Lopomo Beteto* \\ Universidade Nova de Lisboa

\section{Daniel Reed Bergmann** Universidade Presbiteriana Mackenzie}

\begin{abstract}
Market microstructure analysis is currently one of the most intense areas of study in economics and finance. One of the aspects addressed is the securities trading mechanism, to discover the effects of the idiosyncrasies observed in each market. Based on the model developed by Lo and McKinlay (1990), we show that the nontrading process creates a spurious correlation in the observed rates of return, causing a false idea of predictability. To approximate it to reality, we extend the model to a first-order, two-state Markov chain, deriving the moments of the process under this new hypothesis. We also demonstrate that the beta is biased if corrective measures are not taken, due to nonsynchronous data. Finally, using a high-frequency data sample from the Brazilian market, we empirically analyze the model and obtain the probabilities of trading the securities in equilibrium.
\end{abstract}

Key words: Markov chain, nonsynchronous effect, predictability.

\footnotetext{
Received in 11/14/2006; revised in 12/16//2006; accept in 02/03/2007.

Corresponding author:

* Doctoral Candidate in Economics with emphasis on Finance at the Universidade Nova de Lisboa.

**Professor of Finance at Universidade Campolide Campus Presbiteriana Mackenzie. 1099-032 Lisbon Rua da Consolação 896 - São Paulo.

E-mail:danilobeteto@yahoo.com CEP: 01302-907 - São Paulo - SP - Brazil. E-mail: drbergmann@uol.com.br
}

Editor's note: This paper was accepted by Alexsandro Broedel Lopes. 


\section{INTRODUCTION}

$\mathrm{C}$

Currently, market microstructure theory is one of the most active research areas in economics and finance. For certain purposes, such as measurement of the costs of investment strategies and the liquidity of a determined security/market, for example, it is a central element ${ }^{1}$.

To measure the effects caused by the hypothesis that the market has a determined structure, it is necessary to develop measures that can be estimated from an empirical data sample. Then the model can be estimated through the economic and financial plausibility of the results obtained in terms of the estimated parameters.

One of the themes covered by market microstructure theory refers to the securities trading mechanism, particularly the frequency of their trading. Nonsynchronicity or the effect of nontrading appear when time series are collected, especially of the prices of financial assets, in which the data-recording interval does not correspond to the real interval in which they were actually generated. For example, the daily closing prices correspond to those that are collected at the last moment each asset was traded, despite the fact this is not the same moment for all securities.

As mentioned in Campbell et al. (1997), the first author to recognize the importance of the nonsynchronicity of prices was Fischer (1966). More recently, nontrading models have been developed by Atchison et al. (1987), Cohen et al. (1978), Cohen et al. (1979), Cohen et al. (1983), Lo et al. (1990a), Lo et al. (1990b), Lo et al. (1998) and Scholes and Williams (1977).

The importance of nonsynchronous trading occurs because it biases the moments and comoments of an asset's returns, such as the coefficients of the mean, variance, covariance, beta, autocorrelation and cross-correlation. The initial studies of the effects of nonsynchronicity were aimed at empirical applications of the capital asset pricing model (CAPM) and arbitrage pricing theory (APT). However, recently the focus has been the spurious autocorrelation caused by nonsynchronous trading, which creates a false impression of the predictability of the returns even though the real returns are statistically independent.

The objective of this article $^{2}$ is to present the nontrading model developed in Campbell et al. (1997), discussing its effects on some topics of economic and financial theory, and to apply it to a high-frequency data sample of shares traded on the BOVESPA that at the time of the analysis were not part of that exchange's index. The article is organized as follows: Section 2 summarizes the theoretical model, extending the original model to a first-order, two-state Markov chain, and discusses some of the theoretical model's implications on the computation of beta; Section 3 covers the estimation of the modified model, using a sample of Brazilian data; and Section 4 presents the conclusions.

\footnotetext{
${ }^{1}$ For references on the theme, consult Chapter 3 of the work of Campbell et al. (1997).

2 This article was presented at the Fifth Brazilian Meeting on Finance in 2005.
} 


\section{NONSYNCHRONOUS TRADING MODEL}

The approach described here follows the nontrading model presented in Lo and McKinlay (1988). Let $N$ be the number of securities considered, $r_{i t}{ }^{o}$ be the observable rate of return of asset $i$ at time $t$ and $r_{i t}$ be the unobservable rate of return (virtual rate of return ${ }^{3}$ ) of asset $i$ at time $t$.

To model nontrading as a purely statistical result, ignoring the economic and financial reasons for its occurrence, it is necessary to assume that in each period $t$ there is a probability $\pi_{i}$ that asset $i$ is not traded and that the trading occurrences and stochastic process of the virtual returns, $\left\{r_{i t}\right\}$, are independent, as are the other variables considered here. Thus, the nontrading process can be seen as an independent and identically distributed (i.i.d.) series of coin tosses ${ }^{4}$, with different probabilities of trading the $N$ assets considered.

The observable rate of return $r_{i t}^{o}$ depends on the occurrence of trading asset $i$ at time $t$. Let $p_{i t}$ be the price of asset $i$ at time $t$. If asset $i$ is not traded at time $t$, then $r_{i t}^{0}=\log \left(p_{i t} / p_{i(t-1)}\right)=\log 1=0$. Otherwise, if asset $i$ is traded at time $t$, the observable rate of return will be the sum of the virtual rates of return at time $t$ and of all the consecutive moments previous to $t$ when asset $i$ was not traded.

By modeling the returns in this form, we capture the essential characteristic of the nontrading process as a source of spurious autocorrelation: the information first affects the assets that are traded most, with a lag in impact on the returns of assets with low liquidity.

To complete the specification of the nontrading model, suppose that the virtual returns are governed by the following single-factor linear model:

$$
r_{i t}=\mu_{i}+\beta_{i} f_{t}+\varepsilon_{i t} \quad i=1, \ldots, N
$$

where $f_{t}$ is a zero-mean factor, common to all the $N$ securities, and $\varepsilon_{i t}$ is an idiosyncratic error term, independent at all the lags and also of the error terms of the other securities. Since the objective is to treat nontrading as the only source of autocorrelation, assume also that the common factor $f_{t}$ is i.i.d. and independent of $\varepsilon_{i t-k}$ for all $i, t$ and $k$. Thus, the virtual return of each period is random and captures the movements caused by the arrival of new information, along with the idiosyncratic error term.

To derive an explicit expression for the observed returns and deduce their time-series properties, we introduce two random variables:

\footnotetext{
${ }^{3}$ The virtual rates of return represent the changes in the intrinsic value of the security in a market where there are no liquidity restrictions. Hence, the virtual rates of return are considered to be a reflection only of information specific to the company and the economy in general, which under the characteristics of the cited market should be equal to the observed rates of return $r_{i t}^{o}$.

${ }^{4}$ Later this hypothesis will be relaxed, treating the nontrading process as a first-order Markov chain. 30
} 


$$
\begin{gathered}
\delta_{i t}=\left\{\begin{array}{l}
1 \text { (No trading) with probaibility } \pi_{i} \\
1 \text { (Trading) with probaibility } 1-\pi_{i}
\end{array}\right. \\
X_{i t}(k)=\left(1-\delta_{i t}\right) \delta_{i t-1} \delta_{i t-2} \ldots \delta_{i t-k} \quad \operatorname{com} k>0 .
\end{gathered}
$$

By the definition of $X_{i t}(k)$, we have:

$$
X_{i t}(k)=\left\{\begin{array}{l}
1 \text { with probaibility }\left(1-\pi_{i}\right) \pi_{i}^{k} \\
\left.0 \text { with probaibility } 1-\pi_{i}\right) \pi_{i}^{k}
\end{array}\right.
$$

with $X_{i t}(0)=1-\delta_{i t}$, assuming that $\left\{\delta_{i t}\right\}$ is independent of $\left\{\delta_{j t}\right\}$ for $i \neq j$ and i.i.d. in time for $i=1, \ldots, N$.

The variable $\delta_{i t}$ is a dummy, assuming the value 1 if asset $i$ is not traded in period $t$ and 0 otherwise. Similarly, $X_{i t}(k)$ is also a dummy, assuming 1 when asset $i$ is traded at time $t$ but not in the $k$ consecutive periods previous to $t$. Since $\pi_{i} \in(0,1)$, for large $k$ the probability that $X_{i t}(k)$ is zero will be high, given that it is unlikely for a security not to have been traded at least once over an extended previous interval.

According to the new variables introduced, we can express $r_{i t}^{0}$ as:

$$
r_{i t}^{0}=\sum_{0}^{\infty} X_{i t}(k) r_{i t-k} \quad i=1, \ldots, N .
$$

If the asset is not traded at time $t$, then $\delta_{i t}=1$, i.e., $X_{i t}(k)=0, \forall k$, which implies that $r_{i t}^{0}=0$. If the asset is traded at time $t$, the observed return will be equal to the sum of the virtual return at time $t, r_{i t}$, and the $k_{t}$ virtual returns before $t$, with $k_{t}$ a random variable representing the number of consecutive period before $t$ in which asset $i$ was not traded, given by:

$$
k_{t}=\sum_{k=1}^{\infty}\left\{\prod_{j=1}^{k} \delta_{i t-j}\right\}
$$

Although expression (2.4) is more convenient for subsequent calculations, the variable $k_{t}$ can be used so that the definition of the observable rate of return can be understood more intuitively, through:

$$
r_{i t}^{0}=\sum_{k=0}^{k_{t}} r_{i t-k} \quad i=1, \ldots, N .
$$

While expression (2.4) shows that the unobservable rate of return process is a stochastic function of all the past virtual rates of return, expression (2.6) reveals that $r_{i t}{ }^{0}$ also can be understood as a random sum of random terms.

\subsection{Implications of the nontrading model on the observable returns process}

To explain the effects of nontrading on the properties of time series of observable rates of return, we have: 
Proposition 1. For the nontrading process defined implicitly by expressions (2.2) and (2.3), the observable returns process $\left\{r_{i t}{ }^{0}\right\}(i=1, \ldots, N)$ has weak stationarity, with first and second moments given by:

$$
\begin{aligned}
& E\left[r_{i t}^{0}\right]=\mu_{i} \\
& \operatorname{Var}\left[r_{i t}{ }^{0}\right]=\sigma_{i}{ }^{2}+\frac{2 \pi_{i}}{1-\pi_{i}} \mu_{i}^{2} \\
& \operatorname{Cov}\left[r_{i t}^{0}, r_{j t+n}^{0}\right]=\left\{\begin{array}{l}
-\mu_{i}^{2} \pi_{i}^{n} \quad \text { para } i=j, n>0 \\
\frac{\left(1-\pi_{i}\right)\left(1-\pi_{j}\right)}{1-\pi_{i} \pi_{j}} \beta_{i} \beta_{j} \sigma_{f}{ }^{2} \pi_{j}{ }^{n} \quad \text { para } i \neq j, n \geq 0
\end{array}\right. \\
& \operatorname{Corr}\left[r_{i t}^{0}, r_{i t+n}{ }^{0}\right]=\frac{-\mu_{i}^{2} \pi_{i}^{n}}{\sigma_{i}^{2}+\frac{2 \pi_{i}}{1-\pi_{i}} \mu_{i}^{2}}, \quad n>0
\end{aligned}
$$

with $\sigma_{i}^{2} \equiv \operatorname{Var}\left[r_{i t}\right]$ and $\sigma_{f}^{2} \equiv \operatorname{Var}\left[f_{t}\right], E[\square], \operatorname{Var}[\square], \operatorname{Cov}[\square], \operatorname{Corr}[\square]$ being the expectation, variance, covariance and correlation operators.

Demonstration. See Appendix 1.

From expressions (2.7) to (2.10) it can be verified that nontrading does not affect the expected value of the observable rates of return process, but increases the variance because $2 \pi_{i} \mu_{i}^{2} /\left(1-\pi_{i}\right)>0$. It also can be seen from (2.10) that if the expected value of the asset's observable rate of return is greater than zero, i.e., $\mu_{i}>0$, nontrading induces a negative autocorrelation in the observable rates of return for any observed lag, with that autocorrelation decaying exponentially. The intuition behind this result comes from the fact that during the periods when the asset is not traded, the observed rate of return is nil, and during the periods when it is traded, the observed rate of return reverts to the accumulated mean rate of return, with this mean reversion causing the negative serial correlation. For $\mu_{i}=0$, there is no mean reversion, and therefore there is no negative serial correlation.

\subsection{Expansion of the nontrading model to a first-order Markov chain}

In order to relax the hypothesis that the trading process $\left\{\delta_{i t}\right\}$ is i.i.d. ${ }^{5}$, we now assume that it follows a first-order, two-state Markov chain, with the transition probabilities given by:

$$
\begin{aligned}
& \delta_{i t} \\
& 0 \quad 1 \\
& \delta_{i t-1} \quad \begin{array}{ll|l}
\pi_{i} & 1-\pi_{i} \\
1-\pi_{i}^{\prime} & \pi_{i}^{\prime}
\end{array} \mid
\end{aligned}
$$

We can now consider the second proposition.

\footnotetext{
5 Such a hypothesis is very strong, mainly when the security traded has low liquidity, unless a market is considered where there is no information asymmetry or where such information is disseminated slowly. Otherwise, the trading of a security with low liquidity, based on privileged information, would alter the probability of trading the same security at the next instant.
} 
Proposition 2. Let $P_{i t}$ and $Q_{i t}$ be the unconditional probabilities that $\delta_{i t}=0$ and $\delta_{i t}=1$, respectively. Also let $P_{i}$ and $Q_{i}$ be the steady-state probabilities. Under the hypotheses of the preceding paragraph, then:

$$
\begin{aligned}
P_{i} & =\frac{1-\pi_{i}^{\prime}}{2-\left(\pi_{i}+\pi_{i}^{\prime}\right)} \\
Q_{i} & =\frac{1-\pi_{i}}{2-\left(\pi_{i}+\pi_{i}^{\prime}\right)}
\end{aligned}
$$

Also:

$$
\begin{gathered}
E\left[\delta_{i t}\right]=Q_{i} \\
\operatorname{Var}\left[\delta_{i t}\right]=Q_{i}\left(1-Q_{i}\right) \\
\operatorname{Corr}\left[\delta_{i t}, \delta_{i t-1}\right]=Q_{i}\left(\pi_{i}^{\prime}-Q_{i}\right)
\end{gathered}
$$

Demonstration. See Appendix 2.

With these results, just as in the previous subsection, we obtain the moments of the observable rate of return. We then have:

Proposition 3. Assuming that the nontrading process $\left\{\delta_{i t}\right\}$ follows a first-order, two-state Markov chain, with transition probabilities given by (2.11) and steady-state probabilities according to the preceding proposition, we have:

$$
\begin{gathered}
E\left[r_{i t}^{0}\right]=\mu_{i}\left(\pi_{i}^{\prime} Q_{i}+P_{i}\right) \\
\operatorname{Var}\left[r_{i t}^{0}\right]=\mu_{i}^{2}\left[\frac{P_{i}}{\pi_{i}\left(1-\pi_{i}\right)}+\pi_{i}^{\prime} Q_{i}-\left(\pi_{i}^{\prime} Q_{i}+P_{i}\right)^{2}\right] \\
\operatorname{Corr}\left[r_{i t}^{0}, r_{i t-1}^{0}\right]=\mu_{i}^{2}\left[\pi_{i}^{\prime}-\left(\pi_{i}^{\prime} Q_{i}+P_{i}\right)^{2}\right]
\end{gathered}
$$

Demonstration. See Appendix 2.

It can be seen that, ceteris paribus, process $\left\{\delta_{i t}\right\}$ reduces the mean of $r_{i t}^{0}$, since $\pi_{i}^{\prime} Q_{i}+P_{i}<1$ for $0<\pi_{i}, \pi_{\mathrm{i}}^{\prime}<1$, in comparison to the results obtained under the hypothesis that $\left\{\delta_{i t}\right\}$.is i.i.d.

\subsection{Implications in calculating beta}

Beta is defined as the slope of the regression line of the asset's returns in relation to the returns of the market portfolio. To show the effect of not trading the assets, we assume that the nontrading process is given by (2.2) and (2.3).

Let $\beta_{i m, t}$ be the beta of asset $i$ in relation to the market portfolio at time $t$. We then have:

$$
\beta_{i m, t}=\frac{\operatorname{Cov}\left[r_{i t}{ }^{0}, r_{m t}{ }^{0}\right]}{\operatorname{Var}\left[r_{m t}{ }^{0}\right]}
$$

But, by the previous results, we get:

$$
\beta_{i m, t}=\frac{\frac{\left(1-\pi_{i}\right)\left(1-\pi_{m}\right)}{1-\pi_{i} \pi_{m}} \beta_{i} \beta_{m} \sigma_{m}{ }^{2}}{\sigma_{m}{ }^{2}+\frac{2 \pi_{m}}{1-\pi_{m}} \mu_{m}{ }^{2}}=\frac{\left(1-\pi_{i}\right)\left(1-\pi_{m}\right)^{2} \beta_{i} \beta_{m} \sigma_{m}{ }^{2}}{\left(1-\pi_{i} \pi_{m}\right)\left[\sigma_{m}{ }^{2}\left(1-\pi_{m}\right)+2 \pi_{m} \mu_{m}{ }^{2}\right]}
$$

Note that $\beta_{m}=1$, because it is the beta of the market portfolio in relation to the market portfolio factor, i.e., it is the beta of the market portfolio with itself. Since $\pi_{m} \cong 0$, i.e., the 
probability of not trading the assets in the market portfolio is nearly zero (because it would mean that none of the securities in this portfolio were traded), we can simplify expression (2.21) into:

$$
\beta_{i m, t} \cong \frac{\left(1-\pi_{i}\right) \beta_{i} \sigma_{m}^{2}}{\sigma_{m}^{2}}=\left(1-\pi_{i}\right) \beta_{i}
$$

If the asset in question has high liquidity, $\pi_{i} \cong 0$, its beta reduces to $\beta_{i m, t} \cong \beta_{i}$, i.e., the beta is equal to that calculated without considering the asset's liquidity. In the contrary case, where the probability of not trading the asset is near $1, \beta_{i m, t} \cong 0$, due to the effect of the asset's lack of liquidity.

Hence, beta will be biased toward zero if the effect of the assets' nonsynchronous trading is not appropriately considered.

\section{APPLICATION OF THE EXTENDED NONTRADING MODEL IN THE BRAZILIAN CAPITAL MARKET}

This section discusses the application of the nontrading model developed in the previous section, in particular assuming that the nontrading process $\left\{\delta_{i t}\right\}$ follows a first-order, two-state Markov chain. We are especially interested in estimating the Markov chain transition probabilities to obtain an empirical measure of the liquidity level of the assets considered. For this purpose, we chose assets that at the time of the analysis were not part of the BOVESPA index (IBOVESPA) ${ }^{6}$.

Assume a given sequence $\left\{\delta_{i t}\right\}_{t=0}^{T}$ of nontrading indicators. For convenience, we will condition this sequence on the initial nontrading indicator, $\delta_{i 0}$. Let $n_{i 00}, n_{i 01}, n_{i 10}$ e $n_{i 11} n_{i 00}, n_{i 01}, n_{i 10}$, and $n_{i 11}$ be the counts of the pairs of consecutive minutes in which the indicator variables follow the pattern " $00 "$, " $01 "$, " $10 "$, " 11 ", respectively. Therefore, $\sum_{j, k=0,1} n_{i j k}=T$. Given that $\left\{\delta_{i t}\right\}$ follows a first-order Markov chain with transition probabilities given by (2.11), the log-likelihood function of the sequence $\left\{\delta_{i t}\right\}_{t=0}^{T}$ is:

$$
L\left(\left\{\delta_{i t}\right\}_{t=0}^{T} \mid \delta_{i 0}\right)=n_{i o o} \ln \pi_{i}+n_{i 01} \ln \left(1-\pi_{1}\right)+n_{i 10} \ln \left(1-\pi_{i}^{\prime}\right)+n_{i 11} \ln \pi_{i}^{\prime}
$$

The estimators of $\pi_{i}$ and $\pi_{i}^{\prime}$ by maximum likelihood are:

$$
\begin{aligned}
& \hat{\pi}_{i}=\frac{n_{i 00}}{n_{i 00}+n_{i 01}} \\
& \hat{\pi}_{i}^{\prime}=\frac{n_{i 11}}{n_{i 10}+n_{i 11}}
\end{aligned}
$$

and the Fischer information matrix is:

\footnotetext{
${ }^{6}$ We used this criterion to distinguish the level of the assets' liquidity. ${ }^{34}$
} 


$$
i\left(\pi_{i}, \pi_{i}^{\prime}\right)=E\left[\left(\begin{array}{ll}
\frac{n_{i 00}}{\pi_{i}^{2}}+\frac{n_{i 01}}{\left(1-\pi_{i}\right)^{2}} & 0 \\
0 & \frac{n_{i 10}}{\left(1-\pi_{i}^{\prime}\right)^{2}}+\frac{n_{i 11}}{\pi_{i}^{\prime}}
\end{array}\right)\right]
$$

So, the estimates $\pi_{i}$ e $\pi_{i}^{\prime} \pi_{i}$ and $\pi_{i}^{\prime}$ are asymptotically normal and independent, with asymptotic variances estimated by:

$$
\begin{aligned}
& \hat{\sigma}_{\hat{\pi}_{i}}^{2}=\left[\hat{\pi}_{i}\left(1-\hat{\pi}_{i}\right)\left(n_{i 00}+n_{i 01}\right)\right]^{-1} \\
& \hat{\sigma}_{\hat{\pi}_{i}^{\prime}}^{2}=\left[\hat{\pi}_{i}^{\prime}\left(1-\hat{\pi}_{i}^{\prime}\right)\left(n_{i 10}+n_{i 11}\right)\right]^{-1}
\end{aligned}
$$

The data analyzed refer to the period from July 22 to September 18, 2002. Through the GIT function of the Bloomburg terminal, we collected the minute-by-minute trading volumes of the following stocks:

BELG4 - Belgo Mineira PN;

CMET4 - Caemi Metal PN;

CNFB4 - Confab PN;

CTNM4 - Coteminas PN;

GOAU4 - Gerdau Met. PN;

LAME4 - Lojas Americanas PN;

PRGA4 - Perdigão PN;

RPSA4 - Ripasa PN.

As mentioned before, we chose the above stocks because they were not part of the BOVESPA index in the period analyzed. The tables below compile the data and present the estimates obtained:

Table 1: Trading sequences

\begin{tabular}{l|l|l|l|l|l|l}
\hline Ticker & $n_{i 0}$ & $n_{i 1}$ & $n_{i 00}$ & $n_{i 01}$ & $n_{i 10}$ & $n_{i 11}$ \\
\hline BELG4 & 572 & 18.102 & 73 & 499 & 499 & 17.603 \\
\hline CMET4 & 594 & 17.920 & 100 & 654 & 654 & 17.266 \\
\hline CNFB4 & 1.084 & 17.590 & 198 & 886 & 886 & 16.704 \\
\hline CTNM4 & 513 & 18.161 & 72 & 441 & 441 & 17.720 \\
\hline GOAU4 & 914 & 17.760 & 136 & 778 & 778 & 16.982 \\
\hline LAME4 & 418 & 18.256 & 80 & 338 & 338 & 17.918 \\
\hline PRGA4 & 600 & 18.074 & 69 & 531 & 531 & 17.543 \\
\hline RPSA4 & 527 & 18.147 & 45 & 482 & 482 & 17.655 \\
\hline
\end{tabular}

Table 2: Estimates of the parameters

\begin{tabular}{l|l|l|l|l}
\hline Ticker & $\hat{\pi}_{i}$ & $\hat{\sigma}_{\hat{\pi}_{i}}$ & $\hat{\pi}_{i}^{\prime}$ & $\hat{\sigma}_{\hat{\pi}_{i}^{\prime}}$ \\
\hline BELG4 & 0.128 & 0.125 & 0.972 & 0.045 \\
\hline CMET4 & 0.133 & 0.107 & 0.964 & 0.040 \\
\hline CNFB4 & 0.183 & 0.079 & 0.950 & 0.034 \\
\hline CTNM4 & 0.140 & 0.127 & 0.976 & 0.048 \\
\hline GOAU4 & 0.149 & 0.093 & 0.956 & 0.037 \\
\hline LAME4 & 0.191 & 0.124 & 0.981 & 0.055 \\
\hline PRGA4 & 0.115 & 0.128 & 0.971 & 0.044 \\
\hline RPSA4 & 0.085 & 0.156 & 0.973 & 0.046 \\
\hline
\end{tabular}

It can be seen that for the stocks chosen the probability that they are not traded in the next minute, given that they were not traded in the current one, $\hat{\pi}_{i}^{\prime}$, is very high, with the 
estimates being above $95 \%$ for all the assets. Similarly, if there was a trade, the probability that the same would continue occurring, $\hat{\pi}_{i}$, is low (under 20\%) for all the assets in the sample. Intuitively, at least for the sample chosen, there appear to be indications that the transactions were not motivated by insider information, because if this had been the case, after a trade there would have been a sequence of trades representing agents' attempts to take advantage of a profit opportunity, under the hypothesis that the market microstructure enables rapid information dissemination.

The steady-state probabilities, calculated by (2.12) and (2.13) and through the transition probability estimates, as well as the "rough" estimates" of the probabilities of trading and nontrading, $P^{I}\left(\delta_{i t}=0\right)$ and $P^{I}\left(\delta_{i t}=1\right)$, respectively, are given in the table below.

Table 3: Probabilities $P_{i}, Q_{i}$ vs. "crude" estimates

\begin{tabular}{l|l|l|l|l}
\hline Ticker & $P_{i}$ & $Q_{i}$ & $P^{I}\left(\delta_{i t}=0\right.$ & $P^{I}\left(\delta_{i t}=1\right)$ \\
\hline BELG4 & 0.0306 & 0.9694 & 0.0306 & 0.9694 \\
\hline CMET4 & 0.0404 & 0.9596 & 0.0404 & 0.9596 \\
\hline CNFB4 & 0.0580 & 0.9420 & 0.0580 & 0.9420 \\
\hline CTNM4 & 0.0275 & 0.9725 & 0.0275 & 0.9725 \\
\hline GOAU4 & 0.0224 & 0.9776 & 0.0224 & 0.9776 \\
\hline LAME4 & 0.0224 & 0.9776 & 0.0224 & 0.9776 \\
\hline PRGA4 & 0.0321 & 0.9679 & 0.0321 & 0.9679 \\
\hline RPSA4 & 0.0282 & 0.9718 & 0.0282 & 0.9718 \\
\hline
\end{tabular}

It can be seen that to the fourth decimal place there are no differences between the "rough" estimates of the trading and nontrading probabilities of the assets and the steady-state probabilities obtained by maximum likelihood. This result may be a reflection of the fact we are working with high-frequency data (minute-by-minute), besides the fact the assets in the sample have low liquidity.

\section{CONCLUSION}

This article discussed one of the characteristics treated in studying the market microstructure: the securities trading mechanism. It showed that nontrading, when not dealt with adequately, generates spurious autocorrelation in the series of observed rates of return, which causes a false idea of predictability. It also extended the nontrading model, incorporating a first-order, two-state Markov chain to make the model better fit the theoretical evidence found in the literature.

In applying the results to a series of returns of Brazilian stocks, the results showed that for the sample chosen there was no difference between the "rough" estimates and the steady-state probabilities of trading and nontrading the securities. This work can be expanded by incorporating the following alternatives: estimation of the parameters by the Gaussian mixture model (GMM) and analysis of low-frequency data (principally daily).

\footnotetext{
7 The "rough" estimates of the nontrading probability of a security is given by the ratio of the number of observations in which there was no trading in relation to the total number of observations. 
A direct connection of the analysis carried out here can be in a fuller study of the liquidity of financial assets. The transition probabilities can help an asset manager to follow different investment strategies, and can offer a less subjective measure of the holding period of the portfolio, which will affect the VaR calculation.

\section{REFERENCES}

ATCHISON, M.; SIMONDS, R. Nonsynchronous Security Trading and Market Index Autocorrelation. Journal of Finance, v.42, 111-118, 1987.

CAMPBELL, John; LO, A. W.; MACKINLAY, C. The Econometrics of Financial Markets. New Jersey: Princeton University Press, 1997.

COHEN, K.; MAIER, S.; SCHWARTZ, R.; WHITECOMB, D. The Returns Generation Process, Returns Variance and the Effect of Thinness in Security Markets. Journal of Finance, v.33, 149-167, 1978.

COHEN, K.; MAIER, S.; SCHWARTZ, R.; WHITECOMB, D. On the Existence of Serial Correlation in an Efficient Securities Market. TIMS Studies in the Management Sciences, v.11, 151-168, 1979.

COHEN, K.; HAWAWINI, G.; MAIER, S.; SCHWARTZ, R.; WHITECOMB, D. Friction in the Trading Process and the Estimation of Systematic Risk. Journal of Financial Economics, v.12, 263-278, 1983.

DIMSON, E. Risk Measurement when Shares are Subject to Infrequent Trading. Journal of Financial Economics, v.7, 197-226, 1979.

FISHER, L. Some New Stock Market Indexes. Journal of Business, v.39, 191-225, 1966.

LO, A.; MACKINLAY, A. C. Stock Market Prices do not Follow Random Walks: Evidence from a Simple Specification Test. Review of Financial Studies, v.1, 41-66, 1988.

LO, A.; MACKINLAY, A. C. An Econometric Analysis of Nonsychronous-Trading. Journal of Econometrics, v.45, 181-212, 1990a.

LO, A.; MACKINLAY, A. C. When Are Contrarian Profits Due To Stock Market Overreaction. Review of Financial Studies, v.3, 175-208, $1990 \mathrm{~b}$.

SCHOLES, M.; WILLIAMS, J. Estimating Betas from Nonsynchronous Data. Journal of Financial Economics, v.5, 309-328, 1977. 


\section{A Appendix 1: Demonstration of the results of Proposition 1.}

To derive the results of (2.7) - (2.10), the moments and co-moments of the Bernoulli variables $X_{i t}(k)$ are necessary. From (2.3) it follows that

$$
\begin{gathered}
E\left[X_{i t}(k)\right]=\left(1-\pi_{i}\right) \pi_{i}^{k} \\
E\left[X_{i t}{ }^{2}(k)\right]=\left(1-\pi_{i}\right) \pi_{i}^{k}
\end{gathered}
$$

for arbitrary $i, t$ and $k$. To compute $E\left[X_{i t}(k) X_{i t+n}(l)\right]$, we know by (2.3) that:

$$
X_{i t}(k) X_{i t+n}(l)=\left(1-\delta_{i t}\right) \delta_{i t-1} \ldots \delta_{i t-k}\left(1-\delta_{i t+n}\right) \delta_{i t+n-1} \ldots \delta_{i t+n-l} .
$$

If $l \geq n$, then $E\left[X_{i t}(k) X_{i t+n}(l)\right]=0$ with probability 1 , since $\delta_{i t}$ and $\left(1-\delta_{i t}\right)$ are included in the product given by expression (A.3). If $l<n$, then $E\left[X_{i t}(k) X_{i t+n}(l)\right]=\left(1-\pi_{i}\right)^{2} \pi_{i}^{k+l}$. Hence: for

$$
E\left[X_{i t}(k) X_{i t+n}(l)\right]= \begin{cases}\left\{\left(1-\pi_{i}\right)^{2} \pi_{i}^{k+l}\right. & \text { para } l<n \\ 0 & \text { para } l \geq n\end{cases}
$$

From expressions (2.4) and (2.1), we have:

$$
\begin{aligned}
E\left[r_{i t}{ }^{0}\right] & =\sum_{k=0}^{\infty} E\left[X_{i t}(k) r_{i t-k}\right] \\
& =\sum_{k=0}^{\infty} E\left[X_{i t}(k)\right] E\left[r_{i t-k}\right] \\
& =\mu_{i} \sum_{k=0}^{\infty}\left(1-\pi_{i}\right) \pi_{i}^{k} \\
& =\mu_{i}
\end{aligned}
$$

where expression (A.5) follows from the independence of $X_{i t}(k)$ and $r_{i t-k}$. Hence, the result obtained in (2.7) is deduced.

To obtain expression (2.8), we first need to obtain the uncentered second-moment expression for $r_{i t}^{0}$ :

$$
\begin{aligned}
E\left[\left(r_{i t}^{0}\right)^{2}\right] & =E\left[\sum_{k=0}^{\infty} X_{i t}(k) r_{i t-k} \sum_{l=0}^{\infty} X_{i t}(l) r_{i t-l}\right] \\
& =\sum_{k=0}^{\infty} E\left[X_{i t}{ }^{2}(k) r_{i t-k}^{2}\right]+2 \sum_{k=0}^{\infty} \sum_{l=k+1}^{\infty} E\left[X_{i t}(k) X_{i t}(l)\right] E\left[r_{i t-k} r_{i t-l}\right] \\
& =\mu_{i}^{2}+\sigma_{i}^{2}+2 \sum_{k=0}^{\infty} \sum_{l=k+1}^{\infty}\left(1-\pi_{i}\right) \pi_{i}^{l}\left[\mu_{i}^{2}+\sigma_{i}^{2} \theta(k-l)\right], \theta(x)= \begin{cases}0 & \text { para } x \neq 0 \\
1 & \text { para } x=0\end{cases} \\
& =\mu_{i}^{2}+\sigma_{i}^{2}+2\left(1-\pi_{i}\right) \sum_{k=0}^{\infty}\left(\pi_{i}^{k+1} \sum_{l=0}^{\infty} \mu_{i}^{2} \pi_{i}^{l}\right) \\
& =\mu_{i}^{2}+\sigma_{i}^{2}+2 \mu_{i}^{2} \frac{\pi_{i}}{1-\pi_{i}}
\end{aligned}
$$

with $\sigma_{i}^{2}=V\left[r_{i t}^{0}\right]$. This results in (2.8), since 


$$
\begin{aligned}
V\left[r_{i t}^{0}\right] & =E\left[r_{i t}^{0}\right]-\left(E\left[r_{i t}^{0}\right]\right)^{2} \\
& =\mu_{i}^{2}+\sigma_{i}^{2}+2 \mu_{i}^{2} \frac{\pi_{i}}{1-\pi_{i}}-\mu_{i}^{2} \\
& =\sigma_{i}^{2}+\frac{2 \pi_{i}}{1-\pi_{i}} \mu_{i}^{2}
\end{aligned}
$$

The autocovariance of $r_{i t}{ }^{0}$ can be obtained similarly, by calculating:

$$
\begin{aligned}
E\left[r_{i t}^{0} r_{i t+n}^{0}\right] & =E\left[\sum_{k=0}^{\infty} X_{i t}(k) r_{i t-k} \sum_{l=0}^{\infty} X_{i t+n}(l) r_{i t+n-l}\right] \\
& =\sum_{k=0}^{\infty} \sum_{l=0}^{\infty} E\left[X_{i t}(k) X_{i t+n}(l) r_{i t-k} r_{i t+n-l}\right] \\
& =\sum_{k=0}^{\infty} \sum_{l=0}^{n-1}\left(1-\pi_{i}\right)^{2} \pi_{i}^{k+l} E\left[r_{i t-k} r_{i t+n-l}\right] \\
& =\sum_{k=0}^{\infty} \sum_{l=0}^{n-1}\left(1-\pi_{i}\right)^{2} \pi_{i}^{k+l} \mu_{i}^{2} \\
& =\mu_{i}^{2}\left(1-\pi_{i}^{n}\right)
\end{aligned}
$$

Note that the upper limit of the summation in $l$ of expression (A.8) is finite as a result of (A.4). The expression obtained in (A.8) follows from the fact that $\left\{r_{i t}\right\}$ is an i.i.d. sequence and the only combinations of indices $k$ and $l$ that appear in (A.8) are those where $r_{i t-k}$ and $r_{i t+n-l}$ are not contemporary. Therefore, we have:

$$
\begin{aligned}
\operatorname{Cov}\left[r_{i t}^{0} r_{i t+n}^{0}\right] & =E\left[r_{i t}^{0} r_{i t+n}^{0}\right]-E\left[r_{i t}^{0}\right] E\left[r_{i t+n}^{0}\right] \\
& =\mu_{i}^{2}\left(1-\pi_{i}^{n}\right)-\mu_{i}^{2} \\
& =-\mu_{i}^{2} \pi_{i}^{n}
\end{aligned}
$$

The calculation of the cross-covariance between $r_{i t}$ and $r_{j t+n}$ differs only in that the common factors induce a contemporaneous cross-correlation between the virtual returns of assets $i$ and $j$. Using the fact that:

$$
E\left[r_{i t-k} r_{j t+n-l}\right]=\mu_{i} \mu_{j}+\beta_{i} \beta_{j} \sigma_{f}^{2} \theta(l-k-n)
$$

we have:

$$
\begin{aligned}
E\left[r_{i t}^{0} r_{j t+n}^{0}\right] & =E\left[\sum_{k=0}^{\infty} X_{i t}(k) r_{i t-k} \sum_{l=0}^{\infty} X_{j t+n}(l) r_{j t+n-l}\right] \\
& =\sum_{k=0}^{\infty} \sum_{l=0}^{\infty} E\left[X_{i t}(k) X_{j t+n}(l) r_{i t-k} r_{j t+n-l}\right] \\
& =\sum_{k=0}^{\infty} \sum_{l=0}^{\infty} E\left[X_{i t}(k)\right] E\left[X_{j t+n}(l)\right] E\left[r_{i t-k} r_{j t+n-l}\right] \\
& =\sum_{k=0}^{\infty} \sum_{l=0}^{\infty}\left(1-\pi_{i}\right) \pi_{i}^{k}\left(1-\pi_{j}\right) \pi_{j}^{l}\left[\mu_{i} \mu_{j}+\beta_{i} \beta_{j} \sigma_{f}{ }^{2} \theta(l-k-n)\right] \\
& =\mu_{i} \mu_{j}+\frac{\left(1-\pi_{i}\right)\left(1-\pi_{j}\right)}{1-\pi_{i} \pi_{j}} \beta_{i} \beta_{j} \sigma_{f}{ }^{2} \pi_{i}{ }^{n}
\end{aligned}
$$


with expression (A.10) being obtained by the cross-independence of the nontrading process. Thus, to complete the result obtained in (2.9), we only have to work out:

$$
\begin{aligned}
\operatorname{Cov}\left[r_{i t}^{0} r_{j t+n}^{0}\right] & =E\left[r_{i t}^{0} r_{j t+n}^{0}\right]-E\left[r_{i t}^{0}\right] E\left[r_{j t+n}^{0}\right] \\
& =\mu_{i} \mu_{j}+\frac{\left(1-\pi_{i}\right)\left(1-\pi_{j}\right)}{1-\pi_{i} \pi_{j}} \beta_{i} \beta_{j} \sigma_{f}{ }^{2} \pi_{i}^{n}-\mu_{i} \mu_{j} \\
& =\frac{\left(1-\pi_{i}\right)\left(1-\pi_{j}\right)}{1-\pi_{i} \pi_{j}} \beta_{i} \beta_{j} \sigma_{f}{ }^{2} \pi_{i}^{n}
\end{aligned}
$$

Finally, by the previous results obtained and by the definition of $\operatorname{Corr}\left[r_{i t}^{0}, r_{i t+n}^{0}\right]$, we have:

$$
\operatorname{Corr}\left[r_{i t}^{0}, r_{i t+n}^{0}\right]=-\frac{\mu_{i}^{2} \pi_{i}^{n}}{\sigma_{i}^{2}+\frac{2 \pi_{i}}{1-\pi_{i}} \mu_{i}^{2}},
$$

which corresponds to expression (2.10), completing the demonstration.

\section{B Appendix 2: Demonstration of the results of Proposition 2}

Let $P_{i t}$ and $Q_{i t}$ be the unconditional probabilities of $\delta_{i t}=0$ and $\delta_{i t}=1$, respectively. Also let $P_{i}$ and $Q_{i}$ be the steady-state probabilities. Then, by expression (2.11) we obtain:

$$
\begin{aligned}
& P_{i t}=\pi_{i} P_{i t-1}+\left(1-\pi_{i}^{\prime}\right) Q_{i t-1} \\
& Q_{i t}=\left(1-\pi_{i}\right) P_{i t-1}+\pi_{i}^{\prime} Q_{i t-1}
\end{aligned}
$$

In the steady state, $P_{i}=P_{i t}=P_{i, t-1}$ and $Q_{i}=Q_{i t}=Q_{i, t-1}$. Substituting these in the previous expressions, we obtain:

$$
\begin{aligned}
P_{i} & =\frac{1-\pi_{i}^{\prime}}{2-\left(\pi_{i}+\pi_{i}^{\prime}\right)} \\
Q_{i} & =\frac{1-\pi_{i}}{2-\left(\pi_{i}+\pi_{i}^{\prime}\right)}
\end{aligned}
$$

Hence, the mean, variance and first-order autocorrelation of $\delta_{i t}$ in the unconditional steady state are given by:

$$
\begin{gathered}
E\left[\delta_{i t}\right]=Q_{i} \\
V\left[\delta_{i t}\right]=E\left[\delta_{i t}^{2}\right]-\left(E\left[\delta_{i t}\right]\right)^{2}=Q_{i}\left(1-Q_{i}\right) \\
\operatorname{Corr}\left[\delta_{i t}, \delta_{i t-1}\right]=E\left[\delta_{i t} \delta_{i t-1}\right]-E\left[\delta_{i t}\right] E\left[\delta_{i t-1}\right]=Q_{i}\left(\pi_{i}^{\prime}-Q_{i}\right)
\end{gathered}
$$

To calculate the statistics of the observed returns, we utilize expression (2.4). We have:

$$
\begin{aligned}
E\left[r_{i t}^{0}\right] & =\sum_{k=0}^{\infty} E\left[X_{i t}(k)\right] E\left[r_{i t-k}\right] \\
& =\mu_{i}\left[\pi_{i}^{\prime} Q_{i}+\sum_{k=1}^{\infty} P_{i} \pi_{i}^{k-1}\left(1-\pi_{i}\right)\right]=\mu_{i}\left(\pi_{i}^{\prime} Q_{i}+P_{i}\right)
\end{aligned}
$$




$$
\begin{aligned}
V\left[r_{i t}^{0}\right] & =E\left[\left(\sum_{k=0}^{\infty} X_{i t}(k) r_{i t-k}\right)^{2}\right]-\left(E\left[r_{i t}^{0}\right]\right)^{2} \\
& =\mu_{i}^{2}\left[\frac{P_{i}}{\pi_{i}\left(1-\pi_{i}\right)}+\pi_{i}^{\prime} Q_{i}-\left(\pi_{i}^{\prime} Q_{i}+P_{i}\right)^{2}\right]
\end{aligned}
$$

Hence, $\operatorname{Corr}\left[r_{i t}^{0}, r_{i t-1}^{0}\right]$ will be equal to:

$$
\operatorname{Corr}\left[r_{i t}^{0}, r_{i t-1}^{0}\right]=\mu_{i}^{2}\left[\pi_{i}^{\prime}-\left(\pi^{\prime} Q_{i}+P_{i}\right)^{2}\right]
$$

